\title{
UN LUGAR EN EL MUNDO: ARGENTINA EN EL MERCOSUR
}

\section{Norberto Colominas*}

\section{INTRODUCCION Y ANTECEDENTES}

Se asienta en un territorio mayor que el continente europeo, tiene soberanía sobre un espacio ecológico que va del Ecuador a la Antártida (una de las mayores reservas de biodiversidad del mundo), cuenta con doscientos millones de habitantes y genera un producto bruto que ya ronda el millón de millones de dólares.

Estos datos dan una idea de las magnitudes que involucra el acuerdo de integración económica firmado en Asunción en abril de 1990 por Argentina, Brasil, Paraguay y Uruguay, e inaugurado en enero de este año con el nombre de Mercado Común del Sur (Mercosur).

En la actualidad, Chile está negociando con el Mercosur una inclusión del tipo " $4+1$ ", en tanto se han iniciado las conversaciones con los cinco paises del Pacto Andino (Bolivia, Colombia, Ecuador, Perú y Venezuela) y con México en el marco de la Asociación Latinoamericana de Integración (Aladi).

El antecedente inmediato del Tratado de Asunción se remonta a 1986, cuando los presidentes Raúl Alfonsín (Argentina) y José Serney (Brasil) firmaban un acuerdo bilateral de Asociación Preferente.

El Mercosur nacía como una unión aduanera imperfecta, paso obligado hacia el mercado común propiamente dicho que entrará en vigencia a fines del 2005.

Esta unión aduanera se articula sobre dos tipos diferenciados de aranceles: los que se aplican al ingreso del producto de extrazona y los que gravan el intercambio comercial entre los países del Mercosur.

\section{Extrazona}

Existe un Arancel Externo Común (AEC) del 14 por ciento que grava - salvo excepciones- el ingreso de cualquier producto proveniente de los países externos al acuerdo. Las excepciones - como pueden ser los bienes de capital, sobre los que rige un arancel del 2 por ciento- apuntan a facilitar el ingreso de bienes necesarios para el desarrollo económico de los cuatro países. Un buen ejemplo de esto son las computadoras y un alto número de productos informáticos.

\section{Intrazona}

La norma que abarca el 85 por ciento del intercambio, es el libre comercio en el ámbito de los cuatro países, es decir el

\footnotetext{
* Periodista de la Agencia Telam, especializado en Mercosur.
}

flujo comercial sin restricciones arancelarias, aunque existen algunas barreras paraarancelarias - trabas aduaneras, por ejemplo- que son motivo de permanente negociación.

No obstante, esa norma tampoco se cumple en todos los casos, ya que existen listas de excepciones arancelarias, conformadas por productos "sensibles" que cada país quiere preservar de la competencia directa con sus socios. Abarca el 15 por ciento del comercio intrabloque. Paraguay tiene la lista de excepciones más extensa: 399 productos.

Las listas de excepciones constituyen una suerte de amortiguador que facilita la transición no traumática hacia el mercado común en un plazo de 10 años. Son estas excepciones las que vuelven imperfecta la unión aduanera del Mercosur.

\section{MARCO ECONOMICO INTERNACIONAL}

La influencia de los dos grandes países de América del Sur debía ser suficiente para instalar aquí la consigna de los nuevos tiempos: integración o aislamiento.

Esto calzaba con un problema de escala en la circulación internacional de bienes y capitales, que si bien trataba particularmente a las multinacionales, también, aunque en menor medida, limitaba a los capitales de la región.

Desde el punto de vista de aquéllas, los mercados nativos ya resultaban pequeños para las nuevas formas tecnológicas de producir, comercializar y financiar que requerían el abatimiento virtual de las fronteras nacionales. Se imponía una aplicación territorial (recursos), humana (mercados) y espacial (comunicaciones) reunidas en un escenario único: el ámbito económico regional.

En pocos años se sumaron a la Unión Europea los acuerdos comerciales de América del Norte, del AsiaPacífico y del Cono Sur americano. La regionalización hacia la mundialización ya estaba en marcha.

En este contexto, Argentina y Brasil no tenían más alternativa que integrarse e iniciar la construcción de un mercado regional. De lo contrario, y sobre todo para Argentina, casi no habría un lugar en el mundo de la globalización.

\section{LA RELACION BILATERAL}

Durante años, Argentina y Brasil se desarrollaron dentro de sus propios mercados, aunque no por los mismos cami- 
nos. La diferencia estuvo dada por la distinta magnitud de sus economías y por su común pero diferente proceso de sustitución de importaciones.

Aunque en los últimos años no goza de prestigio académico, la sustitución de importaciones constituyó el único camino por el que los países latinoamericanos, grandes y medianos, lograron un nivel de industrialización primaria durante las décadas de los años treinta y cuarenta.

El mercado mundial de entonces lo permitía, desgajado como estaba por la recesión y las zonas monetarias, primero, $y$, después, por la guerra y la escasez de manufacturas exportables.

En los años cincuenta comenzó en Argentina una perdurable puja entre los impulsores de la apertura económica y los defensores del proteccionismo.

En la posguerra, la reconstrucción de Europa y Japón absorbía el grueso de los capitales disponibles. Una parte del dinero sobrante fue canalizado hacia América del Sur por las multinacionales, que se convirtieron en socias de la industrialización sustitutiva.

Esta tuvo dos etapas diferenciadas por la composición de los capitales. En la primera, el actor principal fue el Estado (moneda inconvertible, créditos para la industria, sostén salarial para el mercado interno y protección arancelaria) y los capitales, básicamente, públicos.

La segunda etapa sustitutiva no podía realizarse sin el auxilio del capital extranjero, porque requería grandes inversiones para completar el ciclo productivo. Y aquí comienza la bifurcación.

Argentina sólo lo obtuvo a medias, ya que la incoherencia derivada de aquella puja entre aperturistas y proteccionistas logró frustrar simultáneamente ambos proyectos. No pudo ampliar su mercado nacional ni tampoco modernizar su aparato productivo en el tiempo y las formas que exigía la competencia internacional.

Contemporáneamente, Brasil exigía la competencia internacional, y durante la década de los setenta alcanzó el grado más alto de industrialización en el subcontinente, aunque empañado por una fuerte exclusión social.

A principios de los años noventa - tras el estallido de la hiperinflación y el final abrupto de la presidencia de Alfonsín-el gobierno de Carlos Menem inicia en Argentina el primer intento de apertura económica con apoyo político pleno, consenso social y coyuntura internacional favorable, articulado con la reforma del Estado. El éxito del Plan de Convertibilidad en sus primeros años encumbró la figura del ministro de Economía, Domingo Cavallo.

En la década anterior Brasil había llegado al límite de acumulación competitiva que le permitía el modelo de protección industrial combinado con la promoción de exportaciones. No podía contener la inflación y su estructura productiva había empezado a sufrir los efectos del retraso tecnológico.

Collor de Mello encabezó el primer intento aperturista, aunque frustrado por la falta de apoyo político, las resistencias de un sector importante de la industria y del aparato estatal, y finalmente por las graves irregularidades administrativas que concluyeron con su mandato antes de tiempo.

Fernando Henrique Cardoso recupera rápidamente el tiempo perdido en el desarrollo de aquel proyecto, aunque con marcadas diferencias: el suyo es un gobierno prestigioso e impulsa una apertura administrativa que es el producto de continuas negociaciones con la poderosa industria paulista y con la banca.

\begin{tabular}{|c|c|c|c|}
\hline \multicolumn{4}{|c|}{$\begin{array}{c}\text { PARTICIPACION DEL MERCOSUR RESPECTO } \\
\text { DEL TOTAL DE LLEGADAS DE VISITANTES } \\
\text { EXTRANJEROS } \\
\text { Año } 1990\end{array}$} \\
\hline Pais & $\begin{array}{l}\text { Llegadas } \\
\text { de visitantes } \\
\text { extranjeros }\end{array}$ & $\begin{array}{l}\text { Visitantes } \\
\text { provenientes } \\
\text { del } \\
\text { MERCOSUR }\end{array}$ & $\begin{array}{c}\% \text { de } \\
\text { llegadas del } \\
\text { MERCOSUR } \\
\text { sobre el total } \\
\text { de visitantes } \\
\text { extranjeros }\end{array}$ \\
\hline Argentina & 2.7 & 1.50 & $55,1 \%$ \\
\hline Brasil & 1.23 & & \\
\hline Paraguay & 258.830 & 174.946 & $67,6 \%$ \\
\hline Uruguay & 1.044 .909 & 897.249 & $85,8 \%$ \\
\hline Total & 5.262 .584 & 3.004 .989 & $57,1 \%$ \\
\hline
\end{tabular}

\begin{tabular}{lccc}
\multicolumn{4}{c}{ Año 1991 } \\
\hline Pais & $\begin{array}{c}\text { Llegadas } \\
\text { de visitantes } \\
\text { extranjeros }\end{array}$ & $\begin{array}{c}\text { Visitantes } \\
\text { provenientes } \\
\text { del } \\
\text { MERCOSUR }\end{array}$ & $\begin{array}{c}\% \text { de } \\
\text { llegadas del } \\
\text { MERCOSUR } \\
\text { sobre el total } \\
\text { de visitantes } \\
\text { extranjeros }\end{array}$ \\
\hline Argentina & 2.870 .246 & 1.539 .800 & $53,6 \%$ \\
Brasil & 1.352 .000 & 605.000 & $45,0 \%$ \\
Paraguay & 296.813 & 221.653 & $74,6 \%$ \\
Uruguay & 1.509 .962 & 1.563 .378 & $77,0 \%$ \\
Total & 6.029 .121 & 3.550 .331 & $58,8 \%$ \\
\hline
\end{tabular}

Año 1992

\begin{tabular}{lccc}
\hline País & $\begin{array}{c}\text { Llegadas } \\
\text { de visitantes } \\
\text { extranjeros }\end{array}$ & $\begin{array}{c}\text { Visitantes } \\
\text { provenientes } \\
\text { del } \\
\text { MERCOSUR }\end{array}$ & $\begin{array}{c}\text { \% de } \\
\text { llegadas del } \\
\text { MERCOSUR } \\
\text { sobre el total } \\
\text { de visitantes } \\
\text { extranjeros }\end{array}$ \\
\hline Argentina & 3.030 .913 & 1.557 .695 & $51,4 \%$ \\
Brasil & 1.436 .739 & 823.888 & $57,3 \%$ \\
Paraguay & 281.292 & 172.325 & $61,2 \%$ \\
Uruguay & 1.552 .372 & 1.445 .713 & $93,1 \%$ \\
Total & 6.301 .300 & 3.999 .321 & $63,5 \%$ \\
\hline
\end{tabular}

\begin{tabular}{lccc}
\multicolumn{4}{c}{ Año 1993 } \\
\hline País & $\begin{array}{c}\text { Llegadas } \\
\text { de visitantes } \\
\text { extranjeros }\end{array}$ & $\begin{array}{c}\text { Visitantes } \\
\text { provenientes } \\
\text { del } \\
\text { MERCOSUR }\end{array}$ & $\begin{array}{c}\% \text { de } \\
\text { llegadas del } \\
\text { MERCOSUR } \\
\text { sobre el total } \\
\text { de visitantes } \\
\text { extranjeros }\end{array}$ \\
\hline Argentina & 3.532 .093 & 1.901 .962 & $53,8 \%$ \\
Brasil & $\mathrm{a} / \mathrm{d}$ & $\mathrm{a} / \mathrm{d}$ & $\mathrm{a} / \mathrm{d}$ \\
Paraguay & 336.575 & 203.616 & $60,5 \%$ \\
Uruguay & 1.743 .943 & 1.631 .277 & $93,5 \%$ \\
Total & 5.612 .591 & 3.736 .585 & $66,6 \%$ \\
\hline
\end{tabular}

Era evidente que ambos países debían intentar una integración de sus economías para ampliar los límites de sus propios mercados nacionales, acceder a una mayor especialización y utilizar la integración como palanca para obtener mayores inversiones externas y nuevas tecnologías que apuntalasen la reconversión industrial.

Con sus tiempos y recaudos, Paraguay y Uruguay se asocian al eje argentino-brasileño ampliando el espacio 
económico común, en tanto que Chile ya asoma como el próximo y quinto socio, aunque en una primera etapa su inclusión no será plena.

El Mercosur puede dar respuesta a un largo estancamiento de la economía argentina que se prolongó por más de medio siglo. La integración nacional brasileña fue más diversificada pero aún mantiene una población marginal equivalente a la suma de los habitantes de Argentina, Paraguay y Uruguay.

\section{EL DESARROLLO EXCLUYENTE}

La dinámica asociativa natural tiende a integrar a las zonas más desarrolladas y dejar a las otras libradas a su suerte, repitiendo a escala Mercosur el desarrollo desigual que, aún con diferencias nacionales, fue común a los cuatro países.

Pero como lo natural (lo dado) puja con lo cultural (lo puesto), no es una fatalidad de la historia que "estas crueles provincias" (1) deban permanecer marginadas, estancadas, excluidas por los poderes centrales (léase Buenos Aires, Montevideo y San Pablo-Río).

No debe ser fatalmente así, pero lo será si los gobiernos no adoptan políticas activas para un desarrollo regional integrado; programas federales en base a incentivos múltiples para la radicación de inversiones; planes educativos, sanitarios y de viviendas diferenciales, etcétera.

Aunque no se trata de pedir milagros a gobiernos que deben administrar recursos escasos para atender necesidades múltiples, lo cierto es que el Mercosur ofrece oportunidades para las dos opciones: federalizar e integrar o reconcentrar y seguir excluyendo.

La mayor esperanza para los países del Mercosur es que la integración regional sea no sólo el mejor instrumento para la reconversión, sino para que provincias, estados y regiones del Cono Sur hoy olvidadas puedan encontrar, ellas también, un lugar en el mundo.

\section{EL COMERCIO EXTERIOR DEL MERCOSUR}

\subsection{Argentina}

En lo que va del año, Argentina logró mejorar en gran medida el resultado de su balanza comercial, que en 1994 había arrojado un déficit de 5.700 millones de dólares.

En el primer semestre de 1995 las exportaciones totalizaron 10.662 millones de dólares, un 45 por ciento superiores en comparación con el mismo período del año anterior. A su vez, las importaciones se redujeron a 9.831 millones de dólares, 5 por ciento menos que en igual período de 1994.

El resultado de la balanza comercial para los primeros seis meses del año fue de 831 millones de dólares.

Con relación al destino de las exportaciones, 33 por ciento se dirigió al Mercosur; 21 por ciento a la Unión Europea; 9 por ciento al Nafta, y el 37 por ciento restante al resto del mundo.

\section{ARGENTINA}

ESTRUCTURA DEL COMERCIO CON BRASIL

\begin{tabular}{lccccc}
\hline & MOA & MOI & $\begin{array}{c}\text { MOI } \\
\text { EXCL. MAT } \\
\text { TRANSP }\end{array}$ & PRIMARIOS & COMB \\
1981 & 14 & 24 & 21 & 35 & 26 \\
1982 & 17 & 17 & 15 & 52 & 14 \\
1983 & 32 & 19 & 16 & 36 & 14 \\
1984 & 31 & 18 & 13 & 47 & 4 \\
1985 & 30 & 22 & 17 & 45 & 13 \\
1986 & 30 & 22 & 37 & 45 & 3 \\
1987 & 21 & 39 & 32 & 40 & 0 \\
1988 & 15 & 49 & 44 & 35 & 1 \\
1989 & 23 & 44 & 40 & -31 & 2 \\
1990 & 21 & 39 & 35 & 39 & 0 \\
1991 & 23 & 36 & 29 & 40 & 2 \\
1992 & 14 & 36 & 25 & 43 & 7 \\
1993 & 12 & 39 & 21 & 31 & 18 \\
1994 & 18 & 38 & 20 & 28 & 16 \\
1995 & 15 & 45 & 27 & 27 & 13 \\
\hline
\end{tabular}

\begin{tabular}{|c|c|c|c|c|c|}
\hline \multicolumn{6}{|c|}{$\begin{array}{l}\text { ESTRUCTURA DEL COMERCIO } \\
\text { CON EL RESTO DEL MUNDO }\end{array}$} \\
\hline & $\mathrm{MOA}$ & MOI & $\mathrm{MOI}$ & PRIMARIOS & COMB \\
\hline & \multicolumn{5}{|c|}{ EXCL. MAT } \\
\hline & & & TRANS & & \\
\hline 1981 & 33 & 15 & 15 & 46 & 5 \\
\hline 1982 & 34 & 21 & 19 & 39 & 7 \\
\hline 1983 & 34 & 13 & 12 & 49 & 4 \\
\hline 1984 & 36 & 14 & 13 & 46 & 4 \\
\hline 1985 & 31 & 18 & 17 & 43 & 7 \\
\hline 1986 & 40 & 22 & 20 & 36 & 2 \\
\hline 1987 & 47 & 26 & 24 & 26 & 2 \\
\hline 1988 & 45 & 28 & 26 & 26 & 2 \\
\hline 1989 & 44 & 32 & 30 & 20 & 4 \\
\hline 1990 & 40 & 26 & 25 & 25 & 9 \\
\hline 1991 & 44 & 23 & 22 & 26 & 7 \\
\hline 1992 & 44 & 23 & 19 & 26 & 9 \\
\hline 1993 & 44 & 25 & 23 & 23 & 7 \\
\hline 1994 & 42 & 27 & 24 & 22 & 8 \\
\hline 1995 & 39 & 24 & 23 & 29 & 8 \\
\hline
\end{tabular}

\begin{tabular}{cccccc}
\multicolumn{5}{c}{ ESTRUCTURA TOTAL DE COMERCIO } \\
\hline \multicolumn{7}{c}{ MOA } & MOI & $\begin{array}{c}\text { MOI } \\
\text { EXCL.MAT } \\
\text { TRANSP }\end{array}$ & PRIMARIOS & COMB \\
1981 & 32 & 16 & 15 & 46 & 7 \\
1982 & 33 & 20 & 19 & 40 & 7 \\
1983 & 34 & 13 & 13 & 49 & 4 \\
1984 & 35 & 14 & 17 & 47 & 4 \\
1985 & 31 & 18 & 17 & 13 & 8 \\
1986 & 39 & 22 & 20 & 37 & 2 \\
1987 & 44 & 27 & 25 & 27 & 2 \\
1988 & 43 & 29 & 27 & 36 & 2 \\
1989 & 42 & 33 & 31 & 21 & 4 \\
1990 & 38 & 27 & 26 & 27 & 8 \\
1991 & 41 & 25 & 23 & 28 & 6 \\
1992 & 39 & 24 & 20 & 29 & 9 \\
1993 & 38 & 28 & 23 & 25 & 9 \\
1994 & 36 & 29 & 24 & 23 & 10 \\
1995 & 33 & 30 & 24 & 28 & 9 \\
\hline
\end{tabular}

Las manufacturas de origen industrial (MOI) representaron el 47 por 100 de las exportación al Mercosur, el 12 por 
ciento de las exportaciones a la Unión Europea y el 46 por ciento de las exportaciones al Nafta, de donde resulta evidente el bajo contenido industrial de las exportaciones argentinas al viejo continente.

En el análisis de las exportaciones al Mercosur se aprecia que el 82 por ciento de las mismas se dirigió hacia Brasil, 20 por ciento al Paraguay y 9 por ciento al Uruguay. El incremento de las exportaciones al Mercosur ha sido del 89 por ciento, respecto del mismo período de 1994. Las importaciones argentinas desde el Mercosur disminuyeron un 4 por ciento en igual periodo.

\begin{tabular}{|c|c|c|c|c|c|}
\hline \multicolumn{6}{|c|}{ ARGENTINA } \\
\hline \multicolumn{4}{|c|}{ Principales socios comerciales } & \multicolumn{2}{|c|}{$\begin{array}{c}\text { Exportación por } \\
\text { rubros }\end{array}$} \\
\hline \multicolumn{2}{|c|}{ Exportaciones } & \multicolumn{2}{|c|}{ Importaciones } & & \\
\hline País & Monto* & País & Monto* & Rubro & $\begin{array}{c}\text { Monto } \\
*\end{array}$ \\
\hline Brasil & 2906 & EE.UU & 2076 & Cereales & 1271.8 \\
\hline BE.UU & 878.3 & Brasil & 1998 & $\begin{array}{l}\text { Grasas y } \\
\text { Aceites }\end{array}$ & 1010.7 \\
\hline Chile & 657.1 & Italia & 658.3 & $\begin{array}{l}\text { Combustibl } \\
\text { es y energia }\end{array}$ & 973.2 \\
\hline $\begin{array}{l}\text { Países Ba- } \\
\text { jos }\end{array}$ & 603.3 & Alemania & 623.1 & $\begin{array}{l}\text { Material de } \\
\text { transporte }\end{array}$ & 689.7 \\
\hline Italia & 368.3 & Francia & 529.3 & $\begin{array}{l}\text { Semillas y } \\
\text { frutos }\end{array}$ & 577.9 \\
\hline Paraguay & 339.7 & España & 446.3 & Carnes & 567.3 \\
\hline España & 365.9 & Japón & 347.3 & $\begin{array}{l}\text { Residuos } \\
\text { alimenticios }\end{array}$ & 537.4 \\
\hline Uruguay & 318.7 & China & 288.4 & $\begin{array}{l}\text { Metales y } \\
\text { Manufact. }\end{array}$ & 511.1 \\
\hline Alemania & 321.2 & Chile & 254.5 & $\begin{array}{l}\text { Productos } \\
\text { Químicos }\end{array}$ & 479.7 \\
\hline
\end{tabular}

*Montos en millones de US\$, en el primer semestre de 1995.

Fuente: INDEC (INSTITUTO NACIONAL DE ESTADISTICAS Y CENTROS).

ORIGEN DE LAS IMPORTACIONES ARGENTINAS* (en millones de USS, y \% sobre el total de cada rubro)

\begin{tabular}{l|rr|rr|rr|rr|rr}
\hline & \multicolumn{2}{|c|}{ Nafta } & \multicolumn{2}{|c|}{ U.E } & \multicolumn{2}{|c|}{ Mercosur } & \multicolumn{2}{c|}{ Resto } & \multicolumn{2}{c}{ Total } \\
\hline Total & 1621 & $25 \%$ & 1965 & $30 \%$ & 1419 & $22 \%$ & 1565 & $24 \%$ & 6570 & 100 \\
\hline Bs de K & 610 & $36 \%$ & 566 & $34 \%$ & 173 & $10 \%$ & 336 & $20 \%$ & 1686 & 100 \\
\hline Bs Inter & 560 & $25 \%$ & 584 & $26 \%$ & 628 & $28 \%$ & 466 & $21 \%$ & 2238 & 100 \\
\hline Combust. & 560 & $20 \%$ & 63 & $28 \%$ & 17 & $7 \%$ & 102 & $45 \%$ & 227 & 100 \\
\hline Piez.p/k & 207 & $18 \%$ & 414 & $36 \%$ & 336 & $29 \%$ & 194 & $17 \%$ & 1152 & 100 \\
\hline Bs.cons & 170 & $16 \%$ & 253 & $24 \%$ & 218 & $20 \%$ & 430 & $40 \%$ & 1071 & 100 \\
\hline Vehiculos & 27 & $14 \%$ & 84 & $44 \%$ & 46 & $24 \%$ & 33 & $17 \%$ & 190 & 100
\end{tabular}

*Agrupados en Bienes de Capital (Bs.de K.), Bienes Intermedios (Bs.Inter.) Combustibles, Piezas y Accesorios para Bienes de Capital (Piez.p/k), Bienes de Consumo (Bs.cons.)y Vehículos. Valores correspondientes al primer cuatrimestre de 1995. Fuente: Elaboración propia con datos del INDEC.

Entre los economistas hay coincidencia que en 1995 Argentina batirá el récord de exportaciones, cuyo monto se aproxima a los 21.000 millones, al tiempo que las exportaciones no superarán los 17.000 millones de dólares.

Este vuelco positivo en los resultados de la balanza comercial se explica fundamentalmente por cuatro razones: el aumento de los precios agrícolas y la especialización del país, primer exportador mundial de soja (grano, aceites y derivados); la recesión interna, que se acentuó en el segun- do semestre y liberó mayores saldos exportables; la apreciación del real que abarató los precios argentinos en el mercado de Brasil, y, por fin, la depreciación del dólar —el peso está atado uno a uno con la moneda norteamericanafrente al yen y al marco.

\subsection{Brasil}

El primer objetivo del plan económico impulsado por el presidente Fernando Henrique Cardoso (Plan Real) era que la estabilización de la moneda no afectara el crecimiento. Esto fue ampliamente cumplido, ya que el 1994 el PBI creció 5,7 por ciento con respecto al año anterior y durante el primer trimestre de 1995 el crecimiento fue de 10,4 por ciento con respecto a igual período de 1994.

Este es el tercer año con crecimiento del producto ( 5 por ciento en 1993 y 5,7 por ciento en 1994), en tanto que las estimaciones realizadas por el Instituto de Pesquisa Económica Aplicada (IPEA) señalan que 1995 terminará con un crecimiento del PBI del 6,2 por ciento.

No obstante, considerando el comportamiento de los precios y el resultado de la balanza comercial, se han planteado algunas dudas sobre la consistencia de una tasa de crecimiento como la anunciada.

Al cumplirse el primer semestre la balanza comercial de Brasil había acumulado un déficit de 4.265 millones de dólares, lo que contrasta vivamente con el superávit comercial de 10.400 millones de dólares obtenido durante 1994.

Si se comparan las exportaciones realizadas en el primer semestre con las del mismo período de 1994, las colocaciones de productos primarios se incrementaron un 3,7 por ciento, las de semimanufacturados un 32 por ciento y las de manufacturados un 0,4 por ciento.

A pesar de que los montos exportados muestran un aumento, esto se debió principalmente al aumento de los precios internacionales de las commodities industriales y agricolas, ya que en términos de volúmenes se observan caídas en numerosos rubros.

Si bien la economía brasileña logró mantener una alta tasa de crecimiento y controlar la inflación en torno al 1 por ciento mensual, la apreciación del real frente al dólar y una importante apertura de la economía — si bien "administrada"- abrieron el mercado del país a la penetración de los productos importados.

Del mismo modo, en el primer trimestre la lógica de la lucha antiinflacionaria llevó al gobierno a disponer medidas restrictivas del consumo interno, que había aumentado con la estabilidad de precios y el consecuente retorno del crédito.

\subsection{Uruguay}

La economía de Uruguay es la que menos sintió los remezones del efecto tequila, a tal punto que en un período de fuga de capitales sus bancos pasaron a ser receptores netos, aunque este hecho se relaciona menos con la fortaleza de su economía que con el rol tradicional que cumple en la región su sistema bancario y financiero, equivalente al de la banca suiza en Europa. 
LAS 100 MAYORES EMPRESAS DE BRASIL

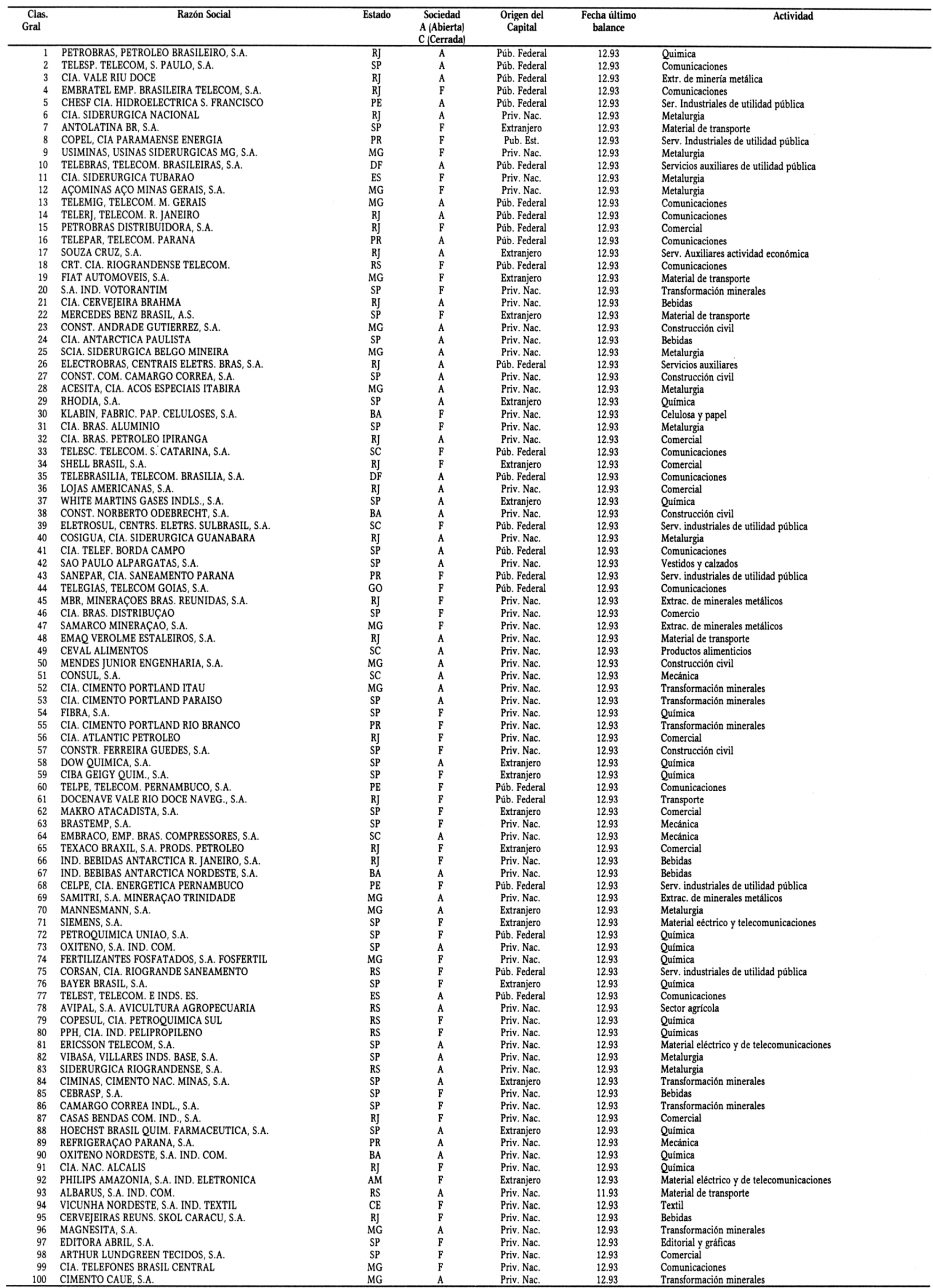


La balanza comercial del país ha sido crecientemente deficitaria desde 1991, ya que el consumo ha crecido más que la producción.

A este proceso no es ajeno el comportamiento macroeconómico de Argentina y Brasil, los dos principales socios comerciales de Uruguay, y la evolución del comercio intraMercosur.

Aproximadamente la mitad del comercio exterior uruguayo se realiza con estos dos países (el 46 por ciento de las exportaciones y el 49,7 por ciento de las importaciones en 1994).

En este sentido, el total de las exportaciones uruguayas registradas en el primer semestre de 1995 alcanzaron un valor de 1.036 millones de dólares $(+17,7)$ - principalmente carnes, lácteos, textiles y cueros-, cuyo destino principal fue el mercado brasileño.

Con relación a igual período de 1994, en el primer semestre de este año Uruguay virtualmente duplicó sus exportaciones a Brasil, mientras que los envíos a Argentina cayeron un 25 por ciento. De este modo, Brasil desplazó a Argentina como primer mercado de las exportaciones uruguayas. Las ventas dirigidas a mercados externos al Mercosur se vieron beneficiadas por el aumento de los precios de los commodities agrícolas.

Sin embargo, a pesar del buen desempeño de las exportaciones, el déficit de balanza comercial trepó a 376 millones de dólares, resultado del aumento de 12,4 por ciento en las importaciones, que llegaron a 1.412 millones de dólares.

Si se compara la composición de las importaciones uruguayas de 1990 con las de 1994 se observa que mientras en el primero de esos años los bienes de consumo representaban el 14,8 por ciento, los intermedios, el 71,8 y los de capital, un 13,4 por ciento, estos valores habían cambiado en 1994 a $27,5,57,9$ y 14,6 por ciento respectivamente.

Lo anterior está mostrando un cambio en la estructura económica del Uruguay: los sectores tradicionales agropecuario e industrial - han tenido desempeños erráticos en términos de crecimiento, en tanto que los rubros de servicios y construcción se han convertido en motores del crecimiento.

Este cambio se observa con claridad en las estadísticas del último lustro, período en el que los servicios crecieron un 47 por ciento y la construcción 43 por ciento frente a una caída neta en el producto industrial y un crecimiento por debajo del promedio en el sector agropecuario.

\subsection{Paraguay}

En la década 1984-1994, la economía paraguaya se sostuvo sobre dos fuertes apoyos: crecimiento económico sostenido de 3,4 por ciento anual acumulativo y una inflación estabilizada en torno al 23 por ciento anual promedio.

Al igual que Uruguay, Paraguay tiene una fuerte concentración de su comercio exterior con los países del Mercosur, por ello el desempeño macroeconómico de sus principales socios tiene un efecto directo sobre el comportamiento de su economía.

En los últimos años, tanto Argentina como Brasil se encontraban en expansión y en consecuencia tenían un com- portamiento similar en términos de demanda de productos paraguayos.

Al producirse la crisis de México la reacción de estos dos países fue diferente; mientras Brasil ha mantenido sus altas tasas de crecimiento, Argentina ha ingresado en una etapa recesiva a partir del segundo semestre del año, lo que se reflejó en la evolución de los intercambios.

Así, las exportaciones totales de Paraguay en el primer semestre se redujeron un 3,3 por ciento y alcanzaron los 404,5 millones de dólares. Como es tradicional, los principales rubros de exportaciones están constituidos por productos primarios (el algodón y la soja representan el 53 por ciento del total exportado).

Las exportaciones paraguayas dirigidas a Brasil crecieron un 127 por ciento con respecto a igual período del año anterior, en tanto que los envíos a Argentina aumentaron sólo el 32 por ciento. Correlativamente, algunos de los sectores de exportación que más han crecido en el primer semestre son aquéllos que han aumentado su colocación en Brasil.

Las importaciones paraguayas aumentaron un 54,6 por ciento en el primer semestre y más de un tercio provinieron de sus socios del Mercosur.

Las importaciones desde Argentina crecieron en ese período un 67 por ciento, totalizando 340 millones de dólares, y en su composición se destaca el sector industrial. Algo similar —en porcentaje y composición-ocurrió con las importaciones realizadas desde Brasil.

\section{EL MERCOSUR Y LA UNION EUROPEA}

El 6 y 7 de diciembre, el balneario uruguayo de Punta del Este será escenario de una reunión cumbre en la que los presidentes de los países del Mercosur y de Chile firmarán el ingreso de ese país al Tratado de Asunción.

El mecanismo de integración será una asociación aduanera limitada por una lista de excepciones (que todavía se está negociando) y será instrumentado con la fórmula "4+1",

Al trabar el Senado norteamericano la vía rápida (fastback) para negociar el ingreso de Chile al Nafta, las expectativas de ese país se reorientaron rápidamente hacia sus vecinos, interesados desde siempre en el acercamiento de Chile al Mercosur.

El 15 de diciembre se firmará en Madrid el acuerdo de libre comercio entre la Unión Europea y el Mercosur más Chile.

Los Estados Unidos tienen mucho que ver con el próximo acuerdo entre el Mercosur y la UE, sobre todo por omisión.

Entre la promisoria Iniciativa para las Américas, lanzada a principios de la década por el entonces presidente George Bush ("Un gran mercado panamericano desde Alaska a Tierra del Fuego"), y el Nafta — su módica realización hasta la fecha- se abrió el espacio para el acuerdo transatlántico del Mercosur y la UE.

Es una curiosidad que a la Unión Europea le resulte más fácil articular un acuerdo de libre comercio con lejanos paises de América del Sur antes que con sus vecinos del Este. 
A la reciproca, el Mercosur se dispone a cruzar el Atlántico antes de haber llegado al río Bravo.

La mundialización nos está acostumbrando a las paradojas.

Nota de la Redacción: Los datos estadísticos de Brasil han sido tomados del Instituto de Pesquisa Económica Aplicada
(IPEA). Los de Argentina, del Instituto Nacional de Estadística y Censos (INDEC). Los correspondientes a Paraguay u Uruguay fueron extractados de La industria y el Mercosur, trabajo elaborado por el licenciado Horacio Cepeda y editado por la Unión Industrial Argentina (UIA). Varias ideas y valiosos datos se deben a la gentileza del periodista y economista Carlos Abalo y a la agencia Telam, que facilitó generosamente su archivo.

\section{RESUMEN}

En 1990, Argentina, Brasil, Uruguay y Paraguay firmaron el acuerdo de integración económica denominado Mercado Común del Sur o Mercosur. En la actualidad, Chile está negociando su inclusión del tipo "4+1" y se han iniciado conversaciones con el Pacto Andino y con México en el seno de la ALADI. Colominas destaca la importancia económica que para estos cuatro países ha supuesto la creación del Mercosur, así como que la integración regional puede superar el desarrollo excluyente de estas economías.

ABSTRACT
In 1990, Argentina, Brazil, Paraguay and Uruguay signed an aggrement of economical integration
denominated Mercado Común del Sur or Mercosur. At present time, Chile is negotiating its inclusion of
the type " $4+1$ " and they are also getting into conversations with the Andean Pact and with México and
ALADI. Colominas points up the economical importance of this accord for these four countries and that
the regional integration can help to overcome the exclusive development of these economies.

